\title{
Pandemic and Stigma COVID-19 in Indonesia
}

\author{
Widjajanti M Santoso ${ }^{1 *}$ Sri Sunarti Purwaningsih ${ }^{2}$ \\ Nina Widyawati ${ }^{1}$ Ade Latifa $^{2}$
}

\author{
${ }^{1}$ Research Center for Society and Culture Indonesian Institute of Sciences Jakarta, Indonesia \\ ${ }^{2}$ Research Center for Population, Indonesian Institute of Sciences, Jakarta, Indonesia \\ *Corresponding Author : widjasantoso@gmail.com
}

\begin{abstract}
The pandemic of COVID-19 destabilizes contemporary social relations. It has many impacts and one of them is a stigma against the infected persons. Stigma usually pictures discriminate behavior toward victims of some diseases such as leprosy or HIV-AIDS and also marginalized groups such as class, age, gender. Most victims of stigma are individuals and communities or nations perceived as lower class than the rest of the population. On the contrary, the pandemic of COVID-19 shows different discrimination as it stigmatizes behavior toward most of the infected people including the well-off people, who struggle toward the virus, more especially doctors, nurses, and other medical assistants. By using personal experiences as a family with COVID-19 and the existing publications including media that cover the issue of the stigma, this article discusses the disrupted social relationships. Stigma emerged particularly in the process of burying the corpse of COVID-19 infected persons where some people of the local communities refuse the corpse to be buried in their area. In an extreme case, some people even dig out the dead bodies. These facts blow social relationships that doctors and other health assistants who are usually categorized as honored persons and in which our culture gives them homage to corpses as something should be treated respectfully. Individuals and communities' members fight to erase the stigmas at the national, and local levels. Governments at the national and local levels have to renovate hotels and other facilitates to give save houses for the infected COVID-19 as quarantine places.
\end{abstract}

Keywords: stigma, discrimination, COVID-19, health workers

\section{INTRODUCTION}

In the pandemic of COVID-19, stigma is seldom discussed. The discussion tends to focus on helping people to get well or prevent them from diseases. According to Stangl et al [1], stigma means a block to health access, participation in caring, obeying medicine direction. Stigma is a part of the pandemic as the HIV/AIDS case mostly in Africa, however, the scale of the COVID-19 is global. The article discusses if there a stigma in the COVID-19 pandemic that exposes the social situation in Indonesia. The stigma is a social problem tehrefor we need to write about social experiences of discriminated behavior. The social experience of the pandemic is best told by Albert Camus's book "La Peste" [2].
However, the COVID-19 pandemic has brought a strange effective global social situation, everything changes, death tolls increase, health system even the best in the world was paralyzed. Most governments in Asia such as in Indonesia watch with fear, with the existing minimal health system, and 250 million populations, haunted the communities. As an effect of stigmatized behavior grows, individuals and communities refuse the health assistants. In an extreme case, some people dig the corpse of the burial. This has never happened before, especially since doctors and nurses are perceived as noble and ranked best in social status. People also give homage to dead bodies, even for somebody we have not known, the passing by corpses are given special treatment in traffic and transportation. The stigma grows 
differently with the common understanding of stigma.

By tracking down media and social media coverage as well as individual insight on being stigmatized the article argues that stigma and discrimination, seldom appear as problematic to the health system and also for the community. Stigma disrupts harmony in culture and everyday life.

\section{STIGMA AND DISCRIMINATION}

There are limited studies about stigma, started by Erving Goffman, a sociologist in 1963. His writing was based on the research about stigmas cross-disciplinary such as sociology, general social sciences, psychology, medicine, and public health [1]. There are several studies about stigma in health such as tuberculosis, leprosy or cancer [3]; the health framework [1]; stigma and discrimination to caregivers of people with schizophrenia [4], family stigma [5].

Comparing the Corona's, with AIDS which can be called a black pandemic, the African continent suffers very hard, and it kills "... productive segment of the population" [6]. AIDS is a dominant health issue and most of the African face other problems such as poverty and tribal war. It challenges the international law between expensive medicine for AIDS to poverty and war. The AIDS pandemic left many orphans and the caring system need further support.

The other pandemic such as the H5N1 caused a problem for rural areas in Southeast Asia, its outbreaks are in Africa, Europe, and the Middle East, [7]. This pandemic has based on poultry and people with mobility, while the source of the virus (poultry) was destroyed and the outbreaks were controlled.

The COVID-19 pandemic destabilizes the whole word [8]. It causes a high death toll even to the most prepared country in terms of health facilities. Žižek views metaphorically as a boat where countries, individuals, and groups alike have to change their mindset, it disrupts social and human relations. Even the concept of communism has to be re-evaluated, rethinking about humans helping humans and the world.

Stigma is a sociological term less studied [9], and there is some confusion because what is described as stigma shows discrimination [3]. Most of the stigma and discrimination studies are about the individual, or groups which perceived as marginal and minority by themselves, as well as by the society. General understanding of stigma selfsocializing individuals such as marking, something different from the society as a whole. However, there are some drawback [3] as stigma is so subtle that it needs something to show on its effect, therefore stigma and discrimination go together. Cases are important, for example in Botswana, $\mathrm{HIV}$ is so pervasive that almost every person is involved. On the individual as well as societal support the system to conquer the stigma.

In the health system, stigma and discrimination are about the victim of some illness, such as HIV/AIDS, TBC. However, the differences in the pandemic of COVID-19 show, more than poverty, it disrupts society. Stigma in the health providers such as medical doctors and nurses make a distance to the patients, by restricting their rapport [5].

Generally, stigma and distinction are considered negative, therefore there are ways, tools, perspectives to combat. Stangl et al. [1], focus on power and vulnerability, complex but fluid. The framework includes social, culture, politics, and economy, moving from the psychological model to social aspects such as drivers and facilitators, stigma 'marking', and stigma manifestations. This framework explores various health stigma, to understand health problems and social aspects, and its interaction with identities. The framework, provides input for the program manager, public policymaker, paramedic, also intervening social policy to minimized the stigmatized and discriminated behavior.

Stigma is a social experience, people faced in their everyday life reality, but also practical by the discrimination they get. It endures belief and ideology. Stangl et al. [1] noticed that stigma has multiple identities, attached to age, sexual orientation, race, ethnic groups, profession, and poverty

Park \& Park [5] categorized stigma on its consequences such as emotional, social, and interpersonal. Emotional is about being marginalized, insignificant so that they felt anger, shame, fear. accordingly stigma would increase by the process of stereotype and prejudice. In the 
health situation, stigma and discrimination would marginalize people who require specific medication.

Levin and Laar, [10] depict threatening situations as an important element. Stigma in this study differs significantly from the usual and general studies about stigma, which is usually seen from dominant to the minority or the weaker social group. Stigma [9] refers to power however subtle rules have put people in their places. Three things are important, the first is to keep people down, targeting less powerful social or individuals, the second is to keep people in, and out. The third is to keep people away, in the health system, sneezing can be considered as the way to keep people away.

In this subject, the persons targeting the stigma include the powerful and dominant group such as the medical supporters that position is very important in the pandemic.

\section{METHOD}

This research uses several methods such as social media as a communication medium, with multiple gadgets, smartphones, and computers. The digital platform such as WhatsApp's group becomes important, in Indonesia, it is the second to Twitter, but it is the handiest [11]. With a click, it opens the world. This article also uses individual experience and social experience of being the COVID-19 victim. The method puts experiences and also the voice of the family. The data are from; the first experience of a mother who loses her first daughter, who is a doctor. The experience of a mother would be used gender method to expose a meaningful process. This is the first-hand experience as one of the researchers is the mother who lost the daughter. Second, the exposed social media coverage of the stigmas and discriminations. The social media exposed the ordinary and the voice of the victim.

\section{COVID-19 PANDEMIC IN INDONESIA}

On March 2, 2020, [12] Kompas.com news, the President Jokowi announced suspected Corona called, called 01 and 02 , afterward the number increase significantly. Although information about the Corona, are immense, social media cover stigma and discrimination. The firstperson suspected of coronavirus in Indonesia was bullied. Viva news.com pointed her achievement as an assistant choreographer of a successful performance in the Asian Games 2019.

The formal apparatus such as the police behave exceedingly by giving the police line, criminalizing and the suspected 01 felt miserable. After the description of the director of the Sulianti Saroso respiratory hospital, the police put out the line. The media has exposed fear causing for example the Ojek (motorcycle public transport) online refused the order from the housing complex of the 01 and 02 houses. The stigmatized 01 and 02 are based on moral, and international mobility and gender issue. Even though the suspected 01 directly report of her possibly being infected by the COVID-19, after her student a Japanese living in Malaysia declares her situation.

\subsection{Social/Physical Distancing, Sympathy and Discrimination}

$\mathrm{R}$ (female, doctor,) died, just after the government socializes social distancing, obviously there were no takziah, people who come to give homage to family. The burial protocol prevents the family to get close only seen from the distance, inside the car. Sympathy came from friends, families, and as medical practitioners and feminist activist, her death was covered in the media, national to international. In social media, the sad news gets 3.3.K Retweets and 8.6K Likes. The family was overwhelmed.

There was a difference of reaction from the $\mathrm{R}$ family's inner circle, they wanted to know more about the process of the Corona infection and medical treatment. In the community, some of the neighbors ignore them and they get labeled as 'coronavirus's family'. Some of the garage reluctance to repair their vehicle, afraid that it contained the virus.

There are cases where the corpses presumed to be COVID-19 victims are being refused for the funeral, despite their already precaution toward the virus. The corpse is cover in plastic and takes a short time to get buried after it is stated as death.

\subsection{Stigma To The Health System}

The first stigma comes from fear of being infected, therefore the community refuses them to come to their home. Their family is being marginalized, however, government transforms some hotels to save houses for them. It has another function because it close to the hospital, the 
facilities are under staff. The stigma runs an informal talk and discussion, one is common found in WA's group. There are several rumors such as the COVID-19 pandemic is about the economy, such as every death cause, the government supports the hospital around 125 million Indonesian rupiahs (IDR). There are also rumors that the hospital pays 9 million IDR for dead bodies counted as a victim of COVID-19 to get that financial support. There are also rumors that the family gets 50 million IDR to be counted and treated as the infected COVID-19. People also believed that the infection of COVID-19 is just a type of flue, patients get well after talking inexpensive paracetamol, and vitamins. They get three times a day of the box of snacks and meals and enjoy their smartphone. The other rumors are about being fooled by the test, he has been tested by swab 5 times but without indications of being sick. According to him, the government pays 4 million IDR for every patient per day for around 24 days before having a letter that concluded of being free of COVID-19. So one patient costs 1 x $4 \mathrm{x}$ IDR $25=100$ million IDR, this is the average, and most of the patients tend to stay longer. The mild patients diagnose as severe to get a respirator which costs around 5-15 million IDR a day, doctors and health supports are marginalized as seeking high income, ignoring their Aesculapius oath.

The reality is not decreasing the impact of stigma because most of the hospitals have to test everybody who came to the hospital and they build an inconvenient tent. However, they still ask them to pay the bill for the inconvenience of the situation. especially in the private and big hospitals where the health system doesn't count. The health supports are stigmatized by their willingness to die for the benefits of their family.

Some of the news tell the story from the COVID19 survivor, about their boredom, because prohibited from direct contact with family members. While others who have passed the hard of the COVID 19 depicts how grateful they are to be cured and very much appreciate the health supporter's help. The National Geographic Indonesia, on their special report in July 2020 depicts persons' experience who get the diseases but survive, and they told the reality of being hospitalized and the severity of the diseases. In most of the cases, the health providers haven't got enough appreciation from the government, as from the minister of health itself.
In the middle of September, the case of a person infected by COVID-19 increases vehemently which shows from the lack of room availability in the hospital. Social media are covered with the news, forwarding messages, videos, photos, and comments on the vulnerability of the health system. The news said that the Ministry of Health has become the biggest cluster of COVID-19 cases and death. Buya Safii' Maarif, a leading academic and religious leader, [13] stated that the president should pay more attention to the death of doctors and health supports, at this moment the death toll is 115 for doctors and people are afraid of its increased. This according to Buya would make Indonesia's society in jeopardy.

In social media, some comments compare Indonesia with New Zealand, in terms of the election. New Zealand who has a low case, halt their election, compared to Indonesia with the high case, and want to continue it. Partially, there is an indication of the misinformation about COVID-19 and people react to it. Kompas dayly news in 20 September, stated some social relationship among them was stigma. This is just an example on the lag of sensitive understanding of stigma in society, in that news, Reisa MD, miss Environment promulgate as COVID-19 house speaker divide function of the state and society. The state is responsible for 3T, testing, tracing, and treating, whereas the society conduct for $3 \mathrm{M}$, menggunakan masker (use masks), menjaga jarak (physical distancing), and menjauhi kerumunan (avoid crowding), mencuci tangan dengan sabun (washing hands with soap). People who are against this rule, are subject to misinformation, that COVID-19 is political propaganda, and only acute problem for the haves. Slightly, it also mentions rumors of who gets infected but limited conference of its reality. This only to show that openness to information is important and significant that we need to educate people, make it a habit to prevent themselves and others from being infected by the COVID-19. The Kompas coverage ends with a question of a government will or a capability?

"Government" in general term tries very hard to cover the death rate, in a sarcasm, Hersubeno Arief journalist turns to political commentary, describes Governor of East Java province, Khofifah Indar Parawangsa, to cover up the black zone. The governor insists to separate causes of death purely COVID-19 and the comorbid or people who died with additional complexities of other diseases such as diabetic or 
hearth attack (Facebook, accessed 21/9/2020). By lying with the statistic, the death toll could be counted lower dramatically and it would make the COVID-19 deadly diseases. As an impact, people's confusion over its seriousness would be increased and it would be struck the $3 \mathrm{~T}$ or the $3 \mathrm{M}$ as a habit to prevent the COVID-19 from spreading.

\section{Conclusion}

There is an irony that doctors and nurses and health assistants also get stigmatized. Stigma is not solely on the patients but also for doctors and health supporters. People in the government, President, and cabinet ministers are perceived to ignore their position in society, therefore the confusion over the COVID-19 and its prevention take more time to reach society's understanding to follow the 3 M. Society's misinformed by sectarian, pseudoscience understanding of the virus. However, in real-time, people are scared due to the posting of an ambulance waiting to enter the Wisma Atlet, the apartment transform to be a Covid's hospital.

The COVID-19 pandemic has shown stigma and discrimination unusual to the general understanding of it. The first paradox is for medical workers such as doctors, nurses, and other medical facilitators. The other is the communitybased stigma and discrimination that might be similar to the general understanding of the intended definition. The first category of the stigma is a paradox where the targeted social groups or individuals are mostly persons in dominant geography and knowledge in the pandemic there are medical representatives.

Accordingly, the social experience of being stigmatized is something new. It is shocking as well as traumatized, the family could feel being marginalized and people make a distance. It prolongs their feeling of loss and anger This is all a new social experience inverting people's general behavior to console the lost the family has to heal by themselves.

For the first stigma, the government at the national and local level provide safe housing such as the hotel changed its function, therefore the medical representatives do not need to come to their houses. The government intervention gives a better solution to the quarantine necessity to the medical representatives as well as to make necessary support for the medical sources.
The stigma for society is rather hard because it needs further socialization not only to push away the fear but also to negotiate with the sources of the stigma. The article suggests understanding the position of the stigma is important especially the multi-level intervention from norms and value, social network, and individual interpersonal intervention.

The way to combat stigma has to go beyond individual support but also to society, by intervening the social norms and values. Dialog about stigma in the COVID- 19 process is important for the actors to disseminate the antistigma messages.

\section{AUTHORS' CONTRIBUTIONS}

All the authors contribute equally

\section{ACKNOWLEDGMENTS}

We thank you for the digital culture program, that provides a conducive sphere for discussion, and all the people that might contribute to the significance of this paper.

\section{REFERENCES}

[1] E.M. Clarke, E.A. Emerson, Design and synthesis of synchronization skeletons using branching-time temporal logic, in D. Kozen (Eds.), Workshop on Logics of Programs, Lecture Notes in Computer Science, vol. 131, Springer, Berlin, Heidelberg, 1981, pp. 52-71. DOI: https://doi.org/10.1007/BFb0025774

[2] J.P. Queille, J. Sifakis, Specification and verification of concurrent systems in CESAR, in: M. Dezani-Ciancaglini and U. Montanari (Eds.), Proceedings of the 5th International Symposium on Programming, Lecture Notes in Computer Science, vol. 137, Springer, Berlin, Heidelberg, 1982, pp. 337-351. DOI: https://doi.org/10.1007/3-54011494-7_22

[3] C. Baier, J-P. Katoen, Principles of Model Checking, MIT Press, 2008.

[4] M. Kwiatkowska, G. Norman, D. Parker, Stochastic model checking, in M. Bernardo, J. Hillston (Eds.), Proceedings of the Formal Methods for the Design of Computer, Communication and Software Systems: Performance Evaluation (SFM), Springer, Berlin, Heidelberg, 2007, pp. 220-270. DOI: https://doi.org/10.1007/978-3-540-72522-0_6 
[5] V. Forejt, M. Kwiatkowska, G. Norman, D. Parker, Automated verification techniques for probabilistic systems, in: M. Bernardo, V. Issarny (Eds.), Proceedings of the Formal Methods for Eternal Networked Software Systems (SFM), Springer, Berlin, Heidelberg, 2011, pp. 53-113. DOI: https://doi.org/10.1007/978-3-642-21455-4_3

[6] G.D. Penna, B. Intrigila, I. Melatti, E. Tronci, M.V. Zilli, Bounded probabilistic model checking with the muralpha verifier, in A.J. Hu, A.K. Martin (Eds.), Proceedings of the Formal Methods in Computer-Aided Design, Springer, Berlin, Heidelberg, 2004, pp. 214-229. DOI: https://doi.org/10.1007/978-3-540-30494-4_16

[7] E. Clarke, O. Grumberg, S. Jha, et al., Counterexample-guided abstraction refinement, in E.A. Emerson, A.P. Sistla (Eds.), Computer-Aided Verification, Springer, Berlin, Heidelberg, 2000, pp. $154-169$. DOI: https://doi.org/10.1007/10722167_15

[8] H. Barringer, R. Kuiper, A. Pnueli, Now you may compose temporal logic specifications, in Proceedings of the Sixteenth Annual ACM Symposium on the Theory of Computing (STOC), ACM, 1984, pp. 51-63. DOI: https://doi.org/10.1145/800057.808665

[9] A. Pnueli, In the transition from global to modular temporal reasoning about programs, in K.R. Apt (Ed.), Logics and Models of Concurrent Systems, Springer, Berlin, Heidelberg, 1984, pp. 123-144. DOI: https://doi.org/10.1007/978-3-642-82453-1_5

[10] B. Meyer, Applying "Design by Contract", Computer 25(10) (1992) 40-51. DOI: https://doi.org/10.1109/2.161279

[11] S. Bensalem, M. Bogza, A. Legay, T.H. Nguyen, J. Sifakis, R. Yan, Incremental component-based construction and verification using invariants, in Proceedings of the Conference on Formal Methods in Computer-Aided Design (FMCAD), IEEE Press, Piscataway, NJ, 2010, pp. 257-256.

[12] H. Barringer, C.S. Pasareanu, D. Giannakopolou, Proof rules for automated compositional verification through learning, in Proc. of the 2nd International Workshop on Specification and Verification of Component Based Systems, 2003.

[13] M.G. Bobaru, C.S. Pasareanu, D. Giannakopoulou, Automated assume-guarantee reasoning by abstraction refinement, in: A. Gupta, S. Malik (Eds.), Proceedings of the Computer Aided Verification, Springer, Berlin, Heidelberg, 2008, pp. 135-148. DOI: https://doi.org/10.1007/978-3540-70545-1_14 